\title{
Epidemiological characteristics of spinal cord injury in Northwest China: a single hospital-based study
}

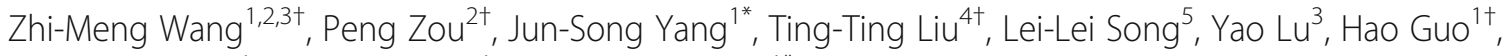
Yuan-Ting Zhao', Tuan-Jiang Liu' ${ }^{1}$ and Ding-Jun Hao ${ }^{1 *}$

\begin{abstract}
Background: While the cities in China in which spinal cord injury (SCl) studies have been conducted previously are at the forefront of medical care, northwest China is relatively underdeveloped economically, and the epidemiological characteristics of $\mathrm{SCl}$ have rarely been reported in this region.

Methods: The SCl epidemiological survey software developed was used to analyze the data of patients treated with SCl from 2014 to 2018. The sociodemographic characteristics of patients, including name, age, sex, and occupation, were recorded. The following medical record data, obtained from physical and radiographic examinations, were included in the study: data on the cause of injury, fracture location, associated injuries, and level of injury. Neurological function was evaluated using the American Spinal Injury Association (ASIA) impairment scale. In addition, the treatment and complications during hospitalization were documented.

Results: A total of 3487 patients with SCI with a mean age of $39.5 \pm 11.2$ years were identified in this study, and the male to female ratio was 2.57:1. The primary cause of SCI was falls (low falls $47.75 \%$, high falls $37.31 \%$ ), followed by traffic accidents (8.98\%), and impact with falling objects (4.39\%). Of all patients, 1786 patients (51.22\%) had complications and other injuries. According to the ASIA impairment scale, the numbers of grade A, B, C, and D injuries were 747 (21.42\%), 688 (19.73\%), 618 (17.72\%), and 1434 (41.12\%), respectively. During the hospitalization period, a total of 1341 patients experienced complications, with a percentage of 38.46\%. Among all complications, pulmonary infection was the most common $(437,32.59 \%)$, followed by hyponatremia $(326,24.31 \%)$, bedsores $(219,16.33 \%)$, urinary tract infection (168, 12.53\%), deep venous thrombosis (157, 11.71\%), and others (34, 2.53\%). Notably, among 3487 patients with $\mathrm{SCl}$, only 528 patients (15.14\%) received long-term rehabilitation treatment.

Conclusion: The incidence of $\mathrm{SCl}$ in northwest China was on the rise with higher proportion in males; fall and the MCVs were the primary causes of $\mathrm{SCl}$. The occupations most threatened by SCl are farmers and workers. The investigation and analysis of the epidemiological characteristics of SCl in respiratory complications are important factors leading to death after SCl, especially when the SCl occurs in the cervical spinal cord. Finally, the significance of SCl rehabilitation should be addressed.
\end{abstract}

Keywords: Spinal injuries, Epidemiology, Northwest China, Retrospective study, Investigation

\footnotetext{
* Correspondence: yangjunsong1988@126.com; dingjun.hao@qq.com

'Zhi-Meng Wang, Peng Zou, Ting-Ting Liu and Hao Guo contributed equally to this work.

${ }^{1}$ Department of Spinal Surgery, Honghui Hospital, Xi'an Jiaotong University, No.76, Nanguo Road, Beilin District, Xi'an 710054, Shaanxi, China

Full list of author information is available at the end of the article
}

(c) The Author(s). 2020 Open Access This article is licensed under a Creative Commons Attribution 4.0 International License, which permits use, sharing, adaptation, distribution and reproduction in any medium or format, as long as you give appropriate credit to the original author(s) and the source, provide a link to the Creative Commons licence, and indicate if changes were made. The images or other third party material in this article are included in the article's Creative Commons licence, unless indicated otherwise in a credit line to the material. If material is not included in the article's Creative Commons licence and your intended use is not permitted by statutory regulation or exceeds the permitted use, you will need to obtain permission directly from the copyright holder. To view a copy of this licence, visit http://creativecommons.org/licenses/by/4.0/ The Creative Commons Public Domain Dedication waiver (http://creativecommons.org/publicdomain/zero/1.0/) applies to the data made available in this article, unless otherwise stated in a credit line to the data. 


\section{Background}

Spinal cord injury (SCI) contributes to serious functional and financial burden and poses a series of problems for the patient's mental health and social stability [1]. SCI is considered to be a major public health problem worldwide, and the incidence of SCI varies greatly between regions [2]. The average annual incidence of SCI in developed countries ranges from 10.4 per million persons to 83 per million persons [3, 4]. In developing countries, SCI has a high incidence of 25.5 per million persons per year [5]. Considering the lack of effective rehabilitation methods for SCI, primary prevention is particularly important.

A few studies have reported the epidemiological characteristics of SCI based on data from hospitals in different parts of China, including Beijing [6], Shanghai [7], Guangdong [8], and Chongqing [9]. In terms of the epidemiology of $\mathrm{SCI}$, the characteristics and occurrence vary greatly; thus, it is important to conduct epidemiological studies on SCI at the population level. While the cities in China in which SCI studies have been conducted previously are at the forefront of medical care, northwest China is relatively underdeveloped economically, and the epidemiological characteristics of SCI have rarely been reported in this region. Hence, this study aims to investigate the epidemiological characteristics of SCI in northwest China, to facilitate optimal medical resource allocation for reducing the financial and social burden of SCI.

\section{Materials and methods}

This study was approved by the Ethics Committee of our hospital. As the hospital is the tertiary trauma center in northwest China, we were able to obtain a large sample size of SCI patients from this hospital. Patients with traumatic SCIs or cauda equina injuries who were admitted to the hospital between 2014 and 2018 were included in the study, while patients who met the following criteria were excluded: (1) vertebral body fractures without SCI, (2) neurological deficit caused by degenerative spinal disease, (3) fatal injuries, and (4) incomplete medical records. The SCI epidemiological survey software developed was used to analyze patient data. The sociodemographic characteristics of patients, including name, age, sex, and occupation, were recorded. The following medical record data, obtained from physical and radiographic examinations, were included in the study: data on the cause of injury, fracture location, associated injuries, and level of injury. Neurological function was evaluated using the American Spinal Injury Association (ASIA) impairment scale. In addition, the treatment and complications during hospitalization were documented.

\section{Statistical analysis}

Mean values are presented as the mean \pm standard deviation (SD). The analysis of variance (ANOVA) and chi-squared tests were used to analyze continuous and categorical data, respectively. A value of $p<0.05$ was considered statistically significant. All statistical analyses were performed using Statistical Product and Service Solution Version 19.0 (SPSS, Inc., Chicago, IL, USA).

\section{Results}

General demographic characteristics of SCI patients between 2014 and 2018

A total of 3487 patients with SCI were identified in this study (Fig. 1). Table 1 shows the general demographic characteristics of SCI patients. Of the 3487 individuals with SCI, 2509 were male (71.95\%) and 978 (28.05\%) were female; the male to female ratio was 2.57:1. Patient age ranged from 18 to 87 years, with a mean age of $39.5 \pm 11.2$ years (male, $36.6 \pm 12.4$ years; female, 42.8 \pm 11.8 years). The proportions of farmers and workers were as high as $59.51 \%$ and $27.04 \%$, respectively.

\section{Etiology of injury and age distribution of patients with $\mathrm{SCl}$}

In this study, the primary cause of SCI was falls (low falls $47.75 \%$, high falls $37.31 \%$ ), followed by traffic accidents $(8.98 \%)$, and impact with falling objects (4.39\%). Furthermore, several unusual causes of SCI, such as those involving sports injuries (1.15\%) and violence injuries $(0.43 \%)$, were also reported. The peak age of patients with SCI ranged from 30 to 49 years, and these patients accounted for $80.99 \%$ of all patients. Further, SCI incidence was negatively correlated with age. The etiologies of injuries among different age groups are shown in Table 2. The common etiologies in the 30-39 years age group were falls (low and high falls) and motor vehicle collisions (MVCs). Low falls were the primary cause of SCI in patients in the 60-year-old age group, while low falls and MVCs were the primary causes of SCIs in patients aged between 20 and 29 years.

\section{Level of injury and associated injuries}

As shown in Fig. 2, an analysis of fracture locations revealed a bimodal distribution. The first peak was seen for the cervical region (41.2\%), especially C4-C6, with the second peak observed for the thoracolumbar region (25.3\%). Of all patients, 1786 patients (51.22\%) had complications and other injuries, including craniocerebral injury $(198,11.09 \%)$, frontofacial injury $(407,22.79 \%)$, chest and abdominal injuries $(359,20.10 \%)$, pelvic injury (258, 14.45\%), and limb fracture (564, 31.58\%). 


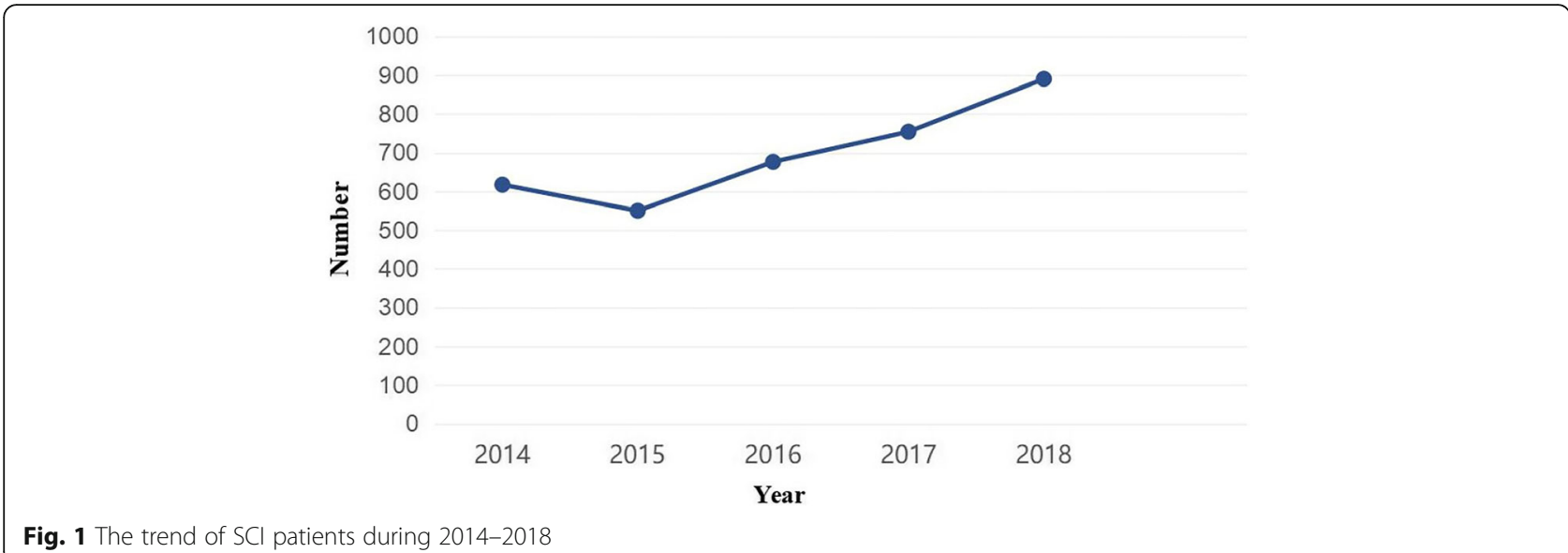

Fig. 1 The trend of SCl patients during 2014-2018

Table 1 Demographic information, etiology of patients with SCl from 2014 to 2018

\begin{tabular}{|c|c|c|c|c|c|c|}
\hline Years & 2014 & 2015 & 2016 & 2017 & 2018 & Total \\
\hline \multicolumn{7}{|l|}{ Age } \\
\hline $0-20$ & 2 & 0 & 1 & 1 & 5 & 9 \\
\hline $20-29$ & 86 & 79 & 93 & 117 & 146 & 521 \\
\hline $30-39$ & 335 & 274 & 361 & 344 & 385 & 1699 \\
\hline $40-49$ & 114 & 107 & 143 & 198 & 228 & 790 \\
\hline $50-59$ & 67 & 85 & 70 & 83 & 109 & 414 \\
\hline$\geq 60$ & 13 & 5 & 8 & 11 & 17 & 54 \\
\hline \multicolumn{7}{|l|}{ Gender } \\
\hline Male & 446 & 413 & 504 & 533 & 613 & 2509 \\
\hline Female & 171 & 137 & 172 & 221 & 277 & 978 \\
\hline \multicolumn{7}{|l|}{ Occupation } \\
\hline Farmer & 387 & 354 & 401 & 442 & 491 & 2075 \\
\hline Worker & 155 & 138 & 179 & 213 & 258 & 943 \\
\hline Government-offices & 43 & 37 & 58 & 61 & 68 & 267 \\
\hline Retired & 8 & 6 & 8 & 15 & 36 & 73 \\
\hline Students & 15 & 10 & 18 & 13 & 19 & 75 \\
\hline Other* & 9 & 5 & 12 & 10 & 18 & 54 \\
\hline \multicolumn{7}{|l|}{ Etiology } \\
\hline Low fall & 301 & 277 & 328 & 358 & 401 & 1665 \\
\hline High fall & 252 & 223 & 241 & 259 & 326 & 1301 \\
\hline MVCs & 39 & 41 & 72 & 77 & 84 & 313 \\
\hline Fall objects & 15 & 4 & 24 & 47 & 63 & 153 \\
\hline Sports & 8 & 4 & 6 & 9 & 13 & 40 \\
\hline Violence & 2 & 1 & 5 & 4 & 3 & 15 \\
\hline Total number & 617 & 550 & 676 & 754 & 890 & 3487 \\
\hline
\end{tabular}

Other* included unemployed individuals and self-employed individuals MVCs motor vehicle collisions

\section{ASIA impairment scale}

According to the ASIA impairment scale, the numbers of grade A, B, C, and D injuries were 747 (21.42\%), 688 (19.73\%), $618(17.72 \%)$, and 1434 (41.12\%), respectively. As shown in Table 3, the different severities of SCI injury were related to different causes: MVCs and high falls, grade A injuries and low falls, grades B and C injuries. Further, different sites of injury were related to different grades of injuries. Injuries to the cervical cord and lumbar cord widely corresponded to ASIA grades A and $\mathrm{D}$, while injuries to the thoracic cord were mostly associated with ASIA grades A and B. Moreover, sacral cord injuries were mainly related to ASIA grade D, as shown in Table 4.

\section{Treatment of $\mathrm{SCl}$ and clinical complications}

Of all patients, $2763(79.24 \%)$ received surgical treatment and $724(20.76 \%)$ received conservative treatment. The duration of hospitalization of patients with SCI ranged from 1 to 378 days, with an average of 17.50 days. During the hospitalization period, a total of 1341 patients experienced complications, with a percentage of $38.46 \%$ (Table 5). Among all complications, pulmonary infection was the most common (437, 32.59\%), followed by hyponatremia $(326,24.31 \%)$, bedsores $(219,16.33 \%)$, urinary

Table 2 Analysis of the etiologies and age distribution among the spinal cord injury (SCl) patients

\begin{tabular}{llllllll}
\hline Etiologies & \multicolumn{1}{l}{ Age } & \multicolumn{7}{l}{ Total } \\
\cline { 2 - 6 } & $0-20$ & $20-29$ & $30-39$ & $40-49$ & $50-59$ & $\geq 60$ & \\
\hline Low fall & 0 & 213 & 733 & 420 & 262 & 37 & 1665 \\
High fall & 1 & 199 & 759 & 282 & 53 & 7 & 1301 \\
MVCs & 4 & 75 & 132 & 58 & 34 & 10 & 313 \\
Falling objects & 0 & 9 & 61 & 21 & 62 & 0 & 153 \\
Sports & 3 & 21 & 10 & 6 & 0 & 0 & 40 \\
Violence & 1 & 4 & 4 & 3 & 3 & 0 & 15 \\
\hline
\end{tabular}

MVCs motor vehicle collisions 


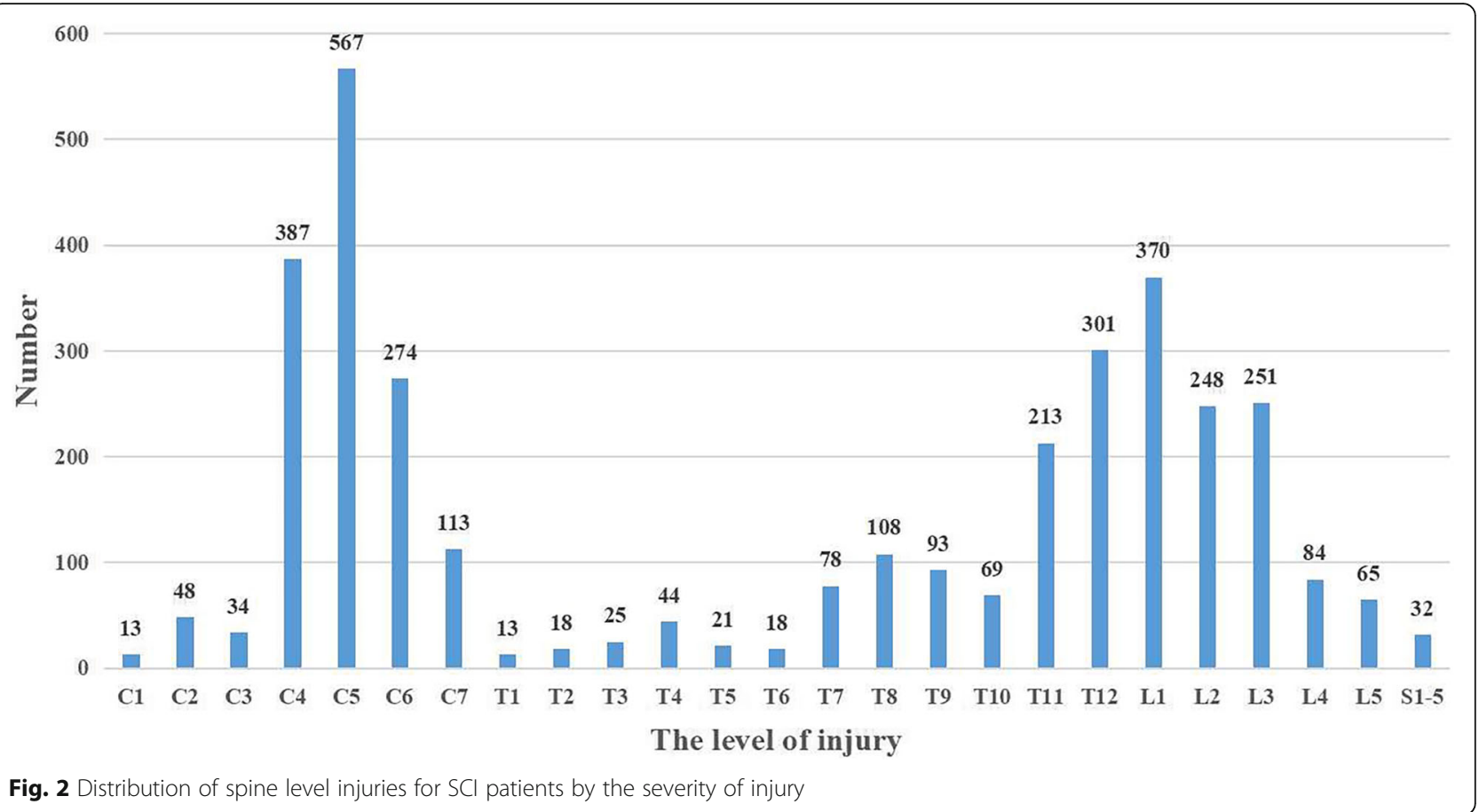

tract infection $(168,12.53 \%)$, deep venous thrombosis (157, 11.71\%), and others (34, 2.53\%). Notably, among 3487 patients with SCI, only 528 patients $(15.14 \%)$ received long-term rehabilitation treatment.

\section{Discussion}

A recent systematic review that included 17 studies in China showed that the epidemiological features of SCI vary among different regions of China; therefore, targeted prevention interventions should be implemented by region. Further, SCI resulting from falls and MVCs may become a major public health concern as the population ages and the economy continues to develop in China [10]. Compared to other areas of China, northwest China has several unique characteristics. First, it is located in the hinterland of mainland China, which mostly consists of plateaus and basins. Compared with

Table 3 Comparison of causes of injury in different degrees of spinal cord injury

\begin{tabular}{|c|c|c|c|c|}
\hline \multirow[t]{2}{*}{ Etiologies } & \multicolumn{4}{|l|}{ ASIA scale } \\
\hline & A (\%) & B (\%) & C (\%) & D (\%) \\
\hline Low fall & $129(17.27)$ & $267(38.81)$ & $293(47.41)$ & 976 (68.06) \\
\hline High fall & $410(54.89)$ & 277 (37.08) & $249(40.29)$ & $365(25.45)$ \\
\hline MVCs & $136(18.21)$ & $78(11.34)$ & $51(8.25)$ & 48 (3.35) \\
\hline Falling objects & $57(7.63)$ & $58(8.43)$ & $14(2.27)$ & $24(1.67)$ \\
\hline Sports & $8(1.07)$ & $5(7.27)$ & $7(1.13)$ & $20(1.39)$ \\
\hline Violence & $7(0.94)$ & $3(4.36)$ & $4(0.65)$ & $1(0.07)$ \\
\hline
\end{tabular}

the economically developed eastern coastal areas, the level of economic and political development is low in this region. In addition, northwest China has a landscape dominated by agriculture and farmers account for the majority of the labor force; low levels of health insurance coverage, education, and household income are also observed in this region. As Xi'an is the economic and cultural center of northwest China, the epidemiological characteristics of SCI patients admitted to the tertiary trauma center in Xi'an are representative of those of SCI patients in northwest China. Based on the epidemiological characteristics of SCI over the past 5 years, we found that SCIs not only cause the impairment of sensory and motor functions below the injury level but also cause several debilitating organ dysfunctions, including those of the respiratory, urinary, and digestive systems, which burdens hospitals with additional costs. Hence, SCIs should not be neglected in northwest China. As the prevention of SCIs is particularly important, comprehensive and detailed epidemiological investigation is fundamental for the development of effective prevention countermeasures.

In this investigation, the male to female ratio in SCI patients was 2.57:1, which was different from the ratios reported in Beijing, Shanghai, Guangdong, Chongqing, Anhui, and Heilongjiang $[6-9,11,12]$. This may be due to the differences in responsibilities and social division of labor between men and women among various provinces of China. Our patients mainly came from the Northwest region, which is economically underdeveloped and resource-poor. The exposure of women to 
Table 4 Analysis of the degrees and segment of the injury among the $\mathrm{SCl}$ patients

\begin{tabular}{|c|c|c|c|c|}
\hline \multirow{2}{*}{$\begin{array}{l}\text { ASIA } \\
\text { scale }\end{array}$} & \multicolumn{4}{|l|}{ The level of injury } \\
\hline & Cervical cord (\%) & Thoracic cord (\%) & Lumbar cord (\%) & Sacral cord (\%) \\
\hline A & $516(31.29)$ & $267(30.20)$ & $96(10.29)$ & $0(0.00)$ \\
\hline B & $249(15.10)$ & $277(31.33)$ & $198(21.22)$ & $0(0.00)$ \\
\hline C & $121(7.33)$ & 78 (8.82) & $167(17.90)$ & $0(0.00)$ \\
\hline D & 763 (46.27) & $0(0.00)$ & $472(50.59)$ & $21(100)$ \\
\hline
\end{tabular}

high-risk industries, such as construction and transportation, has been on the rise. Simultaneously, women are prone to osteoporotic fracture, which may result in higher proportions of women among SCI patients; this has been previously observed in South Africa [13].

The highest proportion of SCIs in northwest China was noted among patients aged between 30 and 49 years. In traditional Chinese culture, it is the responsibility of the young and middle-aged individuals to support their parents and raise their children. Thus, due to the large financial responsibility, they take great risks to provide for their families. Additionally, the roads in northwest China are rugged and undeveloped. Hence, these factors increase the possibility that young and middle-aged individuals experience work-related SCIs, rendering the 3049 years age group a high-risk group. Moreover, as China's aging population is increasing, more elderly people experience SCIs. These patients may have comorbidities such as degenerative spine disease and/or osteoporotic compression fractures. Therefore, the needs of elderly people should be considered in SCI rehabilitation [14]. In our study, the proportions of farmers and workers were as high as $59.51 \%$ and $27.04 \%$, respectively. These values are different from those reported in previous studies conducted in the Guangdong region of China [8], Turkey [15], and Mexico [16]. These discrepancies may be a result of the differences in economic and political environments between regions. In northwest China, a high proportion of the population engages in agriculture-related occupations, which are related to a higher probability of SCI occurrence than any other occupation.

The causes of SCIs include falls (high and low falls), MVCs, impact with falling objects, sports, and violence

Table 5 Clinical complications during the hospitalization

\begin{tabular}{ll}
\hline Complication & Number (\%) \\
\hline Pulmonary infection & $437(32.59 \%)$ \\
Hyponatremia & $326(24.31)$ \\
Bedsore & $219(16.33)$ \\
Urinary tract infection & $168(12.53)$ \\
Deep venous thrombosis & $157(11.71)$ \\
Others $^{\#}$ & $34(2.53)$ \\
\hline
\end{tabular}

Others" include cardiovascular diseases and digestive system disease injuries, and these causes vary across countries and regions. An epidemiological survey conducted in Canada in 2006 showed that MVCs were the main cause of SCIs, while falls became the main cause in 2009 [17, 18]. Another study from seven countries in the Middle-East and North Africa (MENA) region found that MVCs are still the leading cause of SCIs, followed by falls, gunshots, violence, and sports [19]. We found that falls (both from a small and large height) and MVCs were the main causes of SCIs and occurred in nearly all age groups. The incidence of violence also varied by country and region, with the incidence of SCI due to violence being as low as $0.40 \%$ in Beijing [6] and as high as $28.4 \%$ in Brazil [20]. In the same fashion, gunshot wounds were rare in China, mainly due to the strict social security and gun control implemented by the state. As in other developing countries, the per capita car ownership in China is increasing; meanwhile, the improvement in transportation safety measures and the increase in traffic safety awareness have resulted in a decline in traffic-related SCIs.

Similar to the findings of previous studies $[9,21]$, the analysis of injury locations in this study showed a bimodal distribution, with C4-C6 and T11-L1 being the most common locations of injury. Additionally, we found an association between the severity of SCI and the cause of injury. While injuries resulting from MVCs and falls from a large height mostly lead to complete SCIs, mainly of grade A, falls from a small height primarily cause grade D SCIs (incomplete $\mathrm{SCI}$ ). Williams et al. [22] and Thietje et al. [23] reported that patients with grade A SCIs are more likely to experience depressive disorders and suicide; therefore, the families and doctors of these patients should provide more care to these patients to help prevent suicide caused by depression.

The results of this study showed that there were 1341 (36.49\%) patients with complications, with respiratory disease being the most common complication (30.7\%). Respiratory disease is associated with long-term bed rest, lung disease caused by smoking, and rib fractures. Cervical SCIs may affect the function of the diaphragm or intercostal muscle, weaken respiration, and cause coughing, making it difficult to cough out sputum. Such symptoms may also present as complications related to respiratory disease [24]. The higher is the level of SCI, the higher is the risk of pulmonary infection. The risk of 
pulmonary infection can reach up to $>90 \%$ when the SCI occurs above the C5 level, causing dysfunction of the diaphragm [25]. Our results also showed that the average hospitalization duration of SCI patients was 10.70 days, with the longest stay being 94 days, while the hospitalization cost was between 4352 and 456,320 yuan (average 37,850 yuan). It has been highlighted that the hospitalization period of SCI patients is long, the hospitalization cost is high, and the patients have a limited ability to pay for treatment as their income is low; hence, it is difficult to provide comprehensive and effective treatment.

Of all SCI patients, only $15.14 \%$ received rehabilitation. Although this may be related to the low overall rate of SCI rehabilitation in northwest China, it reflects the insufficient attention given to SCI postoperative rehabilitation.

The study has several limitations. First, it was a hospital-based descriptive study on SCI that identified only a small proportion of all SCI patients in northwest China. Second, we collected information of patients admitted to the hospital with SCI, leaving out the information on patients who died in hospitals before admission. Third, training on systematic data collection was not provided, resulting in errors in the data collection process.

\section{Conclusions}

The investigation and analysis of the epidemiological characteristics of SCI in northwest China suggest the requirement of further research on the epidemiology of $\mathrm{SCI}$ in this region. Additionally, education regarding the safety and protection of high-risk groups should be strengthened to reduce the incidence of catastrophic SCIs. Moreover, our study showed that respiratory complications are important factors leading to death after $\mathrm{SCI}$, especially when the SCI occurs in the cervical spinal cord. Finally, the significance of SCI rehabilitation should be addressed.

\section{Abbreviations \\ ANOVA: Analysis of variance; ASIA: American Spinal Injury Association; MENA: Middle-East and North Africa; SCl: Spinal cord injury; SD: Standard deviation}

\section{Acknowledgements}

There is nothing to acknowledge regarding the manuscript.

\section{Authors' contributions}

Ding-Jun Hao and Jun-Song Yang conceived the study design. Zhi-Meng Wang, Peng Zou, Ting-Ting Liu, Jun-Song Yang, Lei-Lei Song, Yao Lu, Hao Guo, Yuan-Ting Zhao, and Tuan-Jiang Liu supervised the data collection. Zhi-Meng Wang drafted the manuscript. Jun-Song Yang contributed to the revision. Ding-Jun Hao and Jun-Song Yang are responsible for this article. The author(s) read and approved the final manuscript.

\section{Funding}

This work was supported by the key project of National Natural Science Foundation of China (No. 81830077 for Ding-Jun Hao) and the Project of
Science and Technology Department of Shaanxi Province (2017ZDXM-SF009; 2019JQ-976).

\section{Availability of data and materials}

The datasets generated during the current study are public at the email dingjun.hao@qq.com.

\section{Ethics approval and consent to participate}

The study was approved by the ethical committee of Honghui hospital of Xi'an Jiaotong University. The patient gave written consent to for research applications of their clinical data. The patient data was anonymized in this study.

\section{Consent for publication}

Consent to publish was obtained from all patients detailed in this study.

\section{Competing interests}

The authors declare no conflict of interests.

\section{Author details}

${ }^{1}$ Department of Spinal Surgery, Honghui Hospital, Xi'an Jiaotong University, No.76, Nanguo Road, Beilin District, Xi'an 710054, Shaanxi, China. ${ }^{2}$ Xi'an Medical University, Xi'an, Shaanxi, China. ${ }^{3}$ Department of Orthopaedics and Trauma, Honghui Hospital, Xi'an Jiaotong University, No.76, Nanguo Road, Beilin District, Xi'an 710054, Shaanxi, China. ${ }^{4}$ Department of Pediatric, Northwest Women's and Children's Hospital, Xi'an, Shaanxi, China. ${ }^{5}$ Qinghai University, Xi'ning, Qinghai, China.

Received: 8 April 2020 Accepted: 25 May 2020

Published online: 09 June 2020

\section{References}

1. Mirzaeva L, Gilhus NE, Lobzin S, Rekand T. Incidence of adult traumatic spinal cord injury in Saint Petersburg, Russia. Spinal Cord. 2019;57:692-9.

2. Hagen EM, Rekand T, Gilhus NE, Gronning M. Traumatic spinal cord injuriesincidence, mechanisms and course. Tidsskr Nor Laegeforen. 2012;132:831-7.

3. Wyndaele M, Wyndaele JJ. Incidence, prevalence and epidemiology of spinal cord injury: what learns a worldwide literature survey? Spinal Cord. 2006:44:523-9.

4. Skolasky RL, Thorpe RJ Jr, Wegener ST, Riley LH 3rd. Complications and mortality in cervical spine surgery: racial differences. Spine. 2014;39:1506-12.

5. Rahimi-Movaghar V, Sayyah MK, Akbari H, Khorramirouz R, Rasouli MR, MoradiLakeh $\mathrm{M}$, et al. Epidemiology of traumatic spinal cord injury in developing countries: a systematic review. Neuroepidemiology. 2013;41:65-85.

6. Li J, Liu G, Zheng Y, Hao C, Zhang Y, Wei B, et al. The epidemiological survey of acute traumatic spinal cord injury (ATSCI) of 2002 in Beijing municipality. Spinal Cord. 2011;49:777-82.

7. Chang FS, Zhang Q, Sun M, Yu HJ, Hu LJ, Wu JH, et al. Epidemiological study of spinal cord injury individuals from halfway houses in Shanghai, China. J Spinal Cord Med. 2018;41:450-8.

8. Yang R, Guo L, Huang L, Wang P, Tang Y, Ye J, et al. Epidemiological characteristics of traumatic spinal cord injury in Guangdong, China. Spine. 2017:42:E555-e61.

9. Ning GZ, Mu ZP, Shangguan L, Tang Y, Li CQ, Zhang ZF, et al. Epidemiological features of traumatic spinal cord injury in Chongqing, China. J Spinal Cord Med. 2016;39:455-60.

10. Yuan S, Shi Z, Cao F, Li J, Feng S. Epidemiological features of spinal cord injury in China: a systematic review. Front Neurol. 2018;9:683.

11. Wang HF, Yin ZS, Chen Y, Duan ZH, Hou S, He J. Epidemiological features of traumatic spinal cord injury in Anhui Province, China. Spinal Cord. 2013;51: 20-2.

12. Chen R, Liu X, Han S, Dong D, Wang Y, Zhang H, et al. Current epidemiological profile and features of traumatic spinal cord injury in Heilongjiang province, Northeast China: implications for monitoring and control. Spinal Cord. 2017;55:399-404.

13. Pefile N, Mothabeng JD, Naidoo S. Profile of patients with spinal cord injuries in Kwazulu-Natal, South Africa: implications for vocational rehabilitation. J Spinal Cord Med. 2018:42:1-10.

14. Kudo D, Miyakoshi N, Hongo M, Kasukawa Y, Ishikawa Y, Ishikawa N, et al. An epidemiological study of traumatic spinal cord injuries in the fastest aging area in Japan. Spinal Cord. 2019;57:509-15. 
15. Guzelkucuk U, Kesikburun S, Demir Y, Aras B, Ozyoruk E, Yilmaz B, et al. Demographic and clinical characteristics of patients with traumatic cervical spinal cord injury: a Turkish hospital-based study. Spinal Cord. 2015;53:441-5.

16. Zarate-Kalfopulos B, Jimenez-Gonzalez A, Reyes-Sanchez A, Robles-Ortiz R, Cabrera-Aldana EE, Rosales-Olivarez LM. Demographic and clinical characteristics of patients with spinal cord injury: a single hospital-based study. Spinal Cord. 2016;54:1016-9.

17. Pickett GE, Campos-Benitez M, Keller JL, Duggal N. Epidemiology of traumatic spinal cord injury in Canada. Spine. 2006;31:799-805.

18. Kattail D, Furlan JC, Fehlings MG. Epidemiology and clinical outcomes of acute spine trauma and spinal cord injury: experience from a specialized spine trauma center in Canada in comparison with a large national registry. J Trauma. 2009;67:936-43.

19. Elshahidi MH, Monir NY, Elzhery MA, Sharaqi AA, Haedaya H, Awad BI, Zaghloul K. Epidemiological characteristics of traumatic spinal cord injury (TSCI) in the Middle-East and North-Africa (MENA) region: a systematic review and meta-analysis. Bull Emerg Trauma. 2018;6:75-89.

20. Barbetta DC, Smanioto TR, Poletto MF, Ferreira R, Lopes A, Casaro FM, et al. Spinal cord injury epidemiological profile in the Sarah Network of Rehabilitation Hospitals-a Brazilian population sample. Spinal Cord Ser Cases. 2018;4:32.

21. Fredo HL, Rizvi SA, Lied B, Ronning P, Helseth E. The epidemiology of traumatic cervical spine fractures: a prospective population study from Norway. Scandinavian journal of trauma, resuscitation and emergency medicine. Scand J Trauma Resus Emerg Med. 2012;20:85.

22. Williams RT, Wilson CS, Heinemann AW, Lazowski LE, Fann JR, Bombardier $\mathrm{CH}$. Identifying depression severity risk factors in persons with traumatic spinal cord injury. Rehabil Psychol. 2014;59:50-6

23. Thietje R, Pouw MH, Schulz AP, Kienast B, Hirschfeld S. Mortality in patients with traumatic spinal cord injury: descriptive analysis of 62 deceased subjects. J Spinal Cord Med. 2011;34:482-7.

24. Jiang F, Jaja BNR, Kurpad SN, Badhiwala JH, Aarabi B, Grossman RG, et al. Acute adverse events after spinal cord injury and their relationship to longterm neurologic and functional outcomes: analysis from the North American Clinical Trials Network for Spinal Cord Injury. Crit Care Med. 2019; 47:e854-62.

25. Fehlings MG, Vaccaro A, Wilson JR, Singh A, Cadotte DW, Harrop JS, et al. Early versus delayed decompression for traumatic cervical spinal cord injury: results of the Surgical Timing in Acute Spinal Cord Injury Study (STASCIS). PLoS One. 2012;7:e32037.

\section{Publisher's Note}

Springer Nature remains neutral with regard to jurisdictional claims in published maps and institutional affiliations.

Ready to submit your research? Choose BMC and benefit from:

- fast, convenient online submission

- thorough peer review by experienced researchers in your field

- rapid publication on acceptance

- support for research data, including large and complex data types

- gold Open Access which fosters wider collaboration and increased citations

- maximum visibility for your research: over $100 \mathrm{M}$ website views per year

At BMC, research is always in progress.

Learn more biomedcentral.com/submissions 